\title{
Katrin Langewiesche, Mobilité religieuse. Changements religieux au Burkina Faso
}

Préf. de J.-P. Olivier de Sardan. Münster, Lit Verlag, coll. « Mainzer Beiträge zur Afrika-Forschung », 8, 2003, 438 p.

\section{Sandra Fancello}

\section{(2) OpenEdition} Journals

Édition électronique

URL : http://journals.openedition.org/assr/3969

DOI : 10.4000/assr.3969

ISSN : $1777-5825$

Éditeur

Éditions de l'EHESS

Édition imprimée

Date de publication : 1 décembre 2006

Pagination : 115-283

ISBN : 2-7132-2124-2

ISSN : 0335-5985

Référence électronique

Sandra Fancello, "Katrin Langewiesche, Mobilité religieuse. Changements religieux au Burkina Faso », Archives de sciences sociales des religions [En ligne], 136 | octobre - décembre 2006, document 136-61, mis en ligne le 13 février 2007, consulté le 21 septembre 2020. URL : http://journals.openedition.org/ assr/3969; DOI : https://doi.org/10.4000/assr.3969

Ce document a été généré automatiquement le 21 septembre 2020.

(C) Archives de sciences sociales des religions 


\section{Katrin Langewiesche, Mobilité religieuse. Changements religieux au Burkina Faso}

Préf. de J.-P. Olivier de Sardan. Münster, Lit Verlag, coll. « Mainzer

Beiträge zur Afrika-Forschung ", 8, 2003, 438 p.

\section{Sandra Fancello}

1 L'ouvrage est tiré d'une thèse de doctorat du même titre, soutenue à l'EHESS en 2001, et centrée sur les ressorts de la conversion religieuse en pays mossi dans la province du Yatênga, au nord du Burkina Faso. La première partie éclaire la formation historique du paysage religieux burkinabé (Les chemins de Dieu probable allusion de l'auteure à l'expression möré «Wênnaam soré » qui désigne souvent le choix religieux) en rappelant la coexistence historique de l'islam et du christianisme et l'expansion quasi simultanée de ces religions concurrentes. Le Burkina Faso est un pays qui se distingue par un contexte de "religiosité tranquille", selon l'expression de René Otayek, comparé à d'autres pays de la région. Le paysage religieux burkinabé combine à la fois une forte présence musulmane sans grand impact politique et une puissante Église catholique qui, bien que minoritaire, a engendré, comme dans d'autres pays africains, la formation d'une élite catholique lettrée : le président Blaise Compaoré, arrivé au pouvoir en 1987 à la suite d'un coup d'État, puis réélu en 1991, 1998 et 2005, est catholique. La seconde partie, plus contemporaine, met l'accent sur la pluralité religieuse, certes à majorité musulmane, qui résulte de la diversité de l'offre religieuse, ainsi que sur la mobilité dans les itinéraires de conversions multiples. L'approche de l'auteure a le mérite d'aborder la mobilité religieuse des individus par une méthode comparative qui intègre la pluralité du champ religieux burkinabé, éclairant ainsi les enjeux de la conversion, et la gestion de l'identité religieuse, comme des dynamiques sociales entrelacées qui participent, pour K. Langewiesche, d'un processus d'individualisation et de modernisation. La pluralité religieuse n'est donc pas une réalité extérieure aux individus, elle est une composante même de leur identité toujours en mouvement, mais aussi de la structure familiale et sociale. 
2 Chacun ne prend part à l'organisation de la vie sociale et communautaire qu'en fonction de ce que chaque communauté religieuse considère comme acceptable. Tandis que protestants et musulmans interdisent la participation aux célébrations traditionnelles (funérailles, danses des masques), "pour les catholiques en revanche, ces coutumes font partie de l'identité mossi, de leur ancrage culturel». Ainsi, «à la différence des premiers missionnaires, [les catholiques] n'interdisent ni les masques, ni les danses qui accompagnent ces cérémonies» (p. 245). Les itinéraire de «conversions multiples" restitués par l'auteure se font, comme souvent, de l'animisme vers le christianisme (Yodogom) ou l'islam (Alpha), soit les deux successivement (Issaka), ou encore, de l'une de ces religions vers le pentecôtisme (Élie, Zourata). Parmi ces conversions multiples, la migration (en Côte d'Ivoire, première destination de la migration burkinabé) joue un rôle majeur, dans les deux sens: de l'islam au christianisme et inversement. Le mariage est également déterminant.

3 La clé de l'ouvrage est probablement le concept de "conversion réversible », symbole même de la mobilité religieuse. Pour illustrer ces conversions réversibles l'auteure analyse le rôle de la napoka, fille du chef de Sonh qui doit assumer les fonctions de la chefferie dans la période transitoire entre le décès de son père et la succession du nouveau chef et cela quelle que soit son appartenance religieuse. La fonction sociale du chef et de la napoka transcende l'appartenance religieuse de l'individu qui ne se définit ici - et n'est perçu - qu'à partir de cette fonction, y compris de la part de sa communauté religieuse. Dans ce rôle inédit et transitoire, la napoka « fait partie de ceux qui font valoir leur identité culturelle mossi pour expliquer leur abandon provisoire de la religion catholique » (p. 263). Cette tolérance sociale, et toute relative, ne dispense pas de «la pression que la communauté musulmane du village fait peser sur les personnes qui pratiquent ouvertement le culte des ancêtres sans avoir une raison reconnue comme légitime» (p. 277). La transition religieuse de la napoka se double d'une mise entre parenthèses du caractère sexué de son rôle social: "c'est le seul moment où une femme a les mêmes pouvoirs qu'un homme (...) elle n'est plus considérée comme une femme", la napoka n'assumant aucune tâche féminine. De même, à l'inverse de la tradition qui veut que l'épouse adopte d'emblée la religion de son mari, ici c'est le mari qui s'aligne sur le statut de la napoka, "puisque c'est un honneur d'être le mari de la napoka». La mobilité religieuse peut donc être, aussi, le résultat d'une négociation entre le statut de l'individu au sein de la société mossi et son appartenance religieuse, celle-ci étant moins définitive que celui-là et donc, par certains aspects, moins contraignante. Paradoxalement, cette souplesse des frontières religieuses a pour but de préserver les rites ancestraux, afin que la pluralité religieuse n'entre jamais en conflit avec les lois coutumières qui régissent la vie sociale et communautaire, socle commun de l'identité mossi, que la tradition et ses rites ont pour but de préserver.

4 Mais les limites de la transaction ne sont pas toujours aussi strictement définies. Ainsi, le «syncrétisme des catholiques » désigne ces derniers comme davantage compromis avec les pratiques traditionnelles - y compris le recours à la magie, que les pentecôtistes, pour leur part, condamnent sévèrement -, alimente les sarcasmes et la littérature, comme l'illustre le récit emprunté à Ousmane Sembene dans son roman Guelwaar (1996). Pourtant, beaucoup de catholiques considèrent certaines pratiques et valeurs traditionnelles comme compatibles avec leur foi et donnent «un sens catholique aux coutumes» (p. 272). Les funérailles sont un des moments critiques au 
sein de familles où coexistent des fidèles de plusieurs confessions. Certains s'y soumettent par obligation, tandis que d'autres évoquent une similitude des valeurs: «Christ a bien dit de respecter tes parents et bien je respecte les parents de ma femme en faisant cela ", explique Philippe, catholique, se rendant aux funérailles des parents de son épouse.

5 L'auteure poursuit l'analyse de ces compromis circonstanciés entre l'identité sociale et l'identité religieuse par l'étude des enjeux identitaires liés à la succession d'un chef coutumier, car « on ne peut pas être naaba et musulman en même temps». Il est donc attendu du futur chef qu'il abandonne sa religion afin de se consacrer aux obligations rituelles de la chefferie, sans entrer en conflit avec sa communauté religieuse. Le statut de naaba garantit au chef un enterrement selon la tradition en dépit du fait qu'il soit musulman. Le cas de Salif Ouedraogo, chef de Sonh, ancien musulman ayant renoncé à cette religion incompatible avec la chefferie, pour finalement devenir catholique, est tout à fait significatif du sens de la mobilité religieuse. Les cas longuement décrits par $\mathrm{K}$. Langewiesche à propos de la napoka, de la bugopoka ou du naaba, amènent à penser qu'il s'agit davantage de négociations, sans confusion des genres, que de syncrétisme.

Ces analyses, toujours enrichies du discours des acteurs et d'une pluralité de points de vue, restituent assez bien le climat religieux burkinabé, ou la négociation, pour ne pas dire la palabre, est au centre des enjeux de la conversion. L'ouvrage est, de plus, agrémenté de photographies qui renforcent les descriptions notamment dans le chapitre consacré aux rituels entourant la mort d'un chef de village (chap. IV). Il est dommage, cependant, que l'auteure ne précise pas plus souvent à quelle dénomination ses propos se rapportent: l'utilisation générique, assumée (p. 20), du terme " protestant » pour désigner les pentecôtistes, même si c'est l'usage local, qui du reste comporte d'autres expressions, et de "protestantisme ", au lieu de "pentecôtisme", même s'il s'agit le plus souvent de l'Église des Assemblées de Dieu, pose un problème. Les éléments de clarifications historiques concernant les autres dénominations "protestantes» des Églises burkinabé (issues de scissions successives au sein des Assemblées de Dieu et qui témoignent du dynamisme de cette mouvance), sont peu documentés. L'Église des Assemblées de Dieu est la dénomination pentecôtiste de loin la plus importante dans ce pays, à laquelle P.-J. Laurent, le spécialiste du pentecôtisme au Burkina Faso, a consacré l'essentiel de ses travaux depuis dix ans et auxquels l'auteure se réfère régulièrement. La réticence de $\mathrm{K}$. Langewiesche à parler $\mathrm{du}$ pentecôtisme en tant que tel l'empêche de saisir l'ampleur de ce mouvement religieux même dans un pays à majorité musulmane. L'approche monographique, certes enrichie de données ethnographiques de première main, de nombreux entretiens, de récits de vie et d'itinéraires de conversions, ne suffit pas à rendre compte de l'impact de cette mouvance transnationale et la complexité de ses rapports avec les autres religions. L'offensive du pentecôtisme sur le front de la religion traditionnelle et de l'islam est à l'origine de tensions parfois assez vives au sein des familles de convertis. La conversion de jeunes musulmans au pentecôtisme est parfois perçue avec inquiétude tant la radicalité du discours de rupture, véhiculé par les pasteurs, paraît sans compromis avec les valeurs de la société traditionnelle. Bien sûr, il demeure de la continuité en deçà de la rupture, et les analyses détaillées restituent assez bien la complexité des stratégies d'acteurs, la souplesse des négociations entre ces mondes religieux. C'est cette souplesse qui fait du Burkina Faso l'un des pays les plus pacifistes de la région malgré sa pluralité religieuse et les inégalités régionales : le Yatênga étant l'une des provinces les plus islamisées du pays, d'où le sentiment que « la pression des musulmans » se fait 
davantage sentir que celle des chrétiens, en minorité dans cette partie du pays. Mais le relativisme de $\mathrm{K}$. Langewiesche tend à masquer les tensions et les conflits parfois réels, la violence de la conversion individuelle, notamment pour les femmes. En témoigne la trop courte allusion à cette veuve catholique, vivant auprès de son fils musulman qui refuse de s'engager à lui promettre un enterrement selon sa foi (p. 277). La femme envisage alors de se convertir à l'islam afin que son enterrement, dont elle ne contrôle pas les modalités, soit en conformité avec sa foi et non l'inverse, qui lui est refusé. La conversion des femmes à l'islam ou au christianisme dépend en partie de la condition faite aux femmes dans chacune de ces religions, ainsi que des attentes des femmes elles-mêmes. La mobilité religieuse peut également être le fait d'une contrainte lorsque la conversion à une religion a pour but d'échapper à une autre, en matière de mariage par exemple, de remariage (lévirat), ou de condition sociale. La mise en perspective des conditions sociales de la conversion, qui sont autant de contraintes, avec les stratégies des acteurs, qui sont autant de marges de manœuvre, éclaire le caractère à la fois pragmatique et consensuel de la mobilité religieuse. 